\title{
Conocimientos, actitudes y prácticas frente al VIH - SIDA en estudiantes de una Universidad Nacional de Ica, 2017
}

\author{
HIV-AIDS knowledge, attitudes and practices among \\ Public University students in Ica, 2017
}

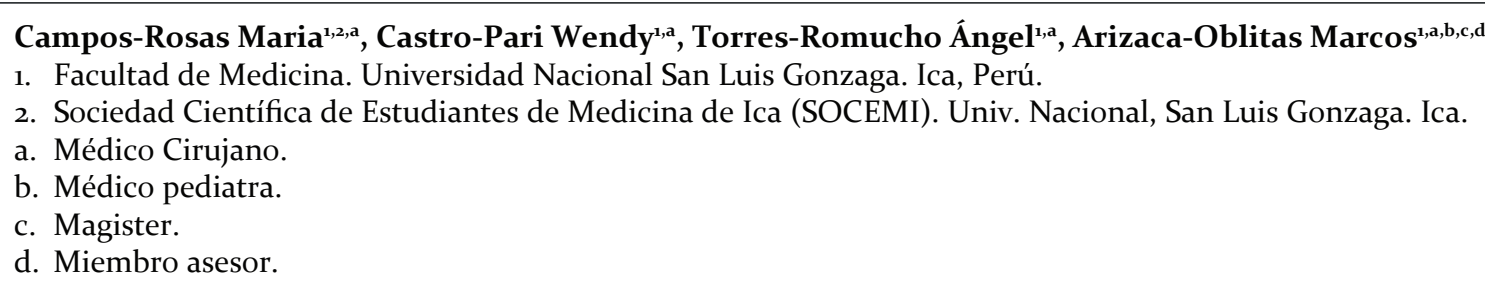

\section{Correspondencia:}

Maria Claudia Campos Rosas Domicilio: Urb. San Miguel Calle Sebastián Barranca B-271

Teléfono: 956616644

Email: maclaudia.cr@gmail.com

Contribuciones De Autoría:

MCR, WCP, ATR, y MAO:

Contribuciones en la concepción y diseño del manuscrito, recolección, análisis e interpretación de los datos; redacción y revisión crítica del contenido del manuscrito y la aprobación final del artículo.

Conflicto De Intereses: No declarados.

Financiamiento: Autofinanciado.

\section{Como Citar}

Campos-Rosas Maria, Castro-Pari Wendy, Torres-Romucho Ángel, Arizaca-Oblitas Marcos. Conocimientos, actitudes y prácticas frente al VIH - SIDA en estudiantes de una Universidad Nacional de Ica, 2017. Rev méd panacea 2018;7(1): 9-21

Recibido: 03 - 03 - 2018

Aceptado: 20 - 03 - 2018

Publicado: 23 - 04 - 2018

\section{RESUMEN}

Objetivo: Identificar los conocimientos, actitudes y prácticas frente al VIH-SIDA en estudiantes de una Universidad Nacional de Ica, 2017. Materiales y métodos: Se realizó un estudio descriptivo, transversal en la Universidad Nacional San Luis Gonzaga de Ica. Participaron estudiantes del cuarto año de estudios, 12 carreras profesionales elegidas mediante muestreo aleatorio simple probabilístico. Se aplicaron 2 instrumentos de recolección de datos: Cuestionario Confidencial sobre Vida Sexual Activa (CCVSA) y Test de Adaptación Colombiana de la Escala de VIH-SIDA - 65, mediante entrevista directa. Se realizó análisis univariado y bivariado, empleando el paquete estadístico SPSS $\otimes$ v 23. Resultados: Se incluyeron 480 estudiantes, el 50,2\% mujeres y el 49,8\% varones; con edad promedio de 22,5 años (19 - 55). El puntaje para el nivel de conocimientos frente al VIH - SIDA, tanto en mujeres y varones se cataloga como intermedio $(50,89 \pm 8,775)$, así como en las actitudes $(29,79 \pm 4,747)$ y prácticas $(19,88 \pm 10,51)$. Los estudiantes de Ciencias de la Salud presentan mayor nivel de conocimientos frente a otras carreras profesionales. La mayoría de los estudiantes (39,2\%) inició su vida sexual entre los 15 y 18 años. El 47,5\% de estudiantes refiere haber usado condón en su primera relación sexual. Conclusiones: Los estudiantes de la Universidad Nacional San Luis Gonzaga de Ica, en el año 2017, poseen un nivel intermedio de conocimientos, de actitudes y prácticas frente al VIH-SIDA. Los alumnos de Ciencias de la Salud reflejan mejores conocimientos y prácticas. Se debe fortalecer aspectos relacionados con la promoción de la salud que orienten a mejores actitudes y prácticas frente a los pacientes y la enfermedad.

Palabras clave: VIH, serodiagnóstico del SIDA, Conocimientos, Actitudes y Práctica en Salud, prácticas sexuales, servicios de salud para estudiantes. (Fuente: DeCS BIREME).

\begin{abstract}
Objective: To identify HIV/AIDS knowledge, attitudes and practices among National University students in Ica, 2017. Materials and methods: A descriptive, cross-sectional study at the Universidad Nacional San Luis Gonzaga de Ica, was performed. 480 students belonging to the fourth academic year, 12 areers chosen by probabilistic random sampling, have participated. Two instruments of data collection were applied: Cuestionario Confidencial sobre Vida Sexual Activa (CCVSA) and Test de Adaptación Colombiana de la Escala de VIH/SIDA - 65, through direct interview. Univariate and bivariate analyzes using the statistical package SPSS ${ }^{\circledR} \vee 23$, were performed. Results: 480 students were included, $50.2 \%$ women and $49.8 \%$ men; with an average age of 22.49 years. The score for the level of knowledge regarding HIV/ AIDS, both in women and men, is classified as intermediate $(50,89 \pm 8,775)$, as well as in attitudes $(29,79 \pm 4,747)$ and practices $(\mathrm{xx} \pm \mathrm{xx})$. The students of Health Sciences have a higher level knowledge compared to other professional careers. Most students (39,2\%) started their sexual life, between 15 and 18 years old. Condom use in their first sexual relationship was reported in $47.5 \%$ of students. Conclusions: The students of Universidad Nacional San Luis Gonzaga de Ica at 2017 have an intermediate level of knowledge, attitudes and practices regarding HIV-AIDS. The students of Health Sciences reflect better knowledge and practices. It should strengthen aspects related to health promotion that guide better attitudes and practices towards patients and the disease.
\end{abstract}

Keywords: HIV, AIDS serodiagnosis, Health Knowledge, Attitudes, Practice, student Health services. (Source: MeSH NLM). 


\section{INTRODUCCIÓN}

A consecuencia de las metas alcanzadas por los Objetivos del Desarrollo del Milenio relacionados con el virus de la inmunodeficiencia humana $(\mathrm{VIH})$, desde el año 2000 al 2015 se ha producido una disminución notoria de las nuevas infecciones por el $\mathrm{VIH}$ y las muertes relacionadas por el SIDA. Sin embargo, el VIH sigue siendo un problema de salud pública mundial, ya que ha cobrado 34 millones de vidas hasta la actualidad y 1,2 millones de personas murieron en todo el mundo a causa de esta enfermedad solo en el 2014 (1). Aproximadamente en América Latina y el Caribe viven alrededor de 2 millones de personas con $\mathrm{VIH}$, casi un $30 \%$ no sabe que lo tienen, siendo diagnosticados en etapas muy avanzadas.

El VIH-SIDA sigue siendo uno de los más graves problemas de salud pública a nivel mundial, especialmente en los países de ingresos bajos o medianos, siendo los jóvenes de 15 a 24 años quienes representan un tercio del número total de personas con nuevas infecciones por el VIH a nivel mundial; por lo que, son necesarios buenos conocimientos sobre el tema para adoptar conductas que reduzcan el riesgo de transmisión del VIH, en esta población tan susceptible (2).

En el 2015, fueron diagnosticados en Perú 1060 personas con SIDA y 4589 infectados con $\mathrm{VIH}$; asimismo, de 1983 al 2015, Ica presentó 1489 casos notificados de SIDA, ubicándose en cuarto lugar. A nivel nacional, el $77 \%$ casos notificados de SIDA son varones y el $23 \%$ son mujeres, mientras que la mediana de la edad de casos de SIDA es de 31 años; entonces, es posible que el 50\% de los casos se hayan expuesto al VIH antes de los 20 años (3). En Perú, tan sólo en el 2016, habitaban cerca de 70,000 personas con $\mathrm{VIH}$, de este grupo una de cada cuatro personas desconocía su estado serológico, asimismo, para ese año se presentaron cerca de 2,700 nuevas infecciones, según el último reporte de la ONUSIDA (4). En ese sentido, el Ministerio de Salud del Perú remarca la necesidad de evitar las situaciones que nos pone en riesgo de adquirir el VIH (5).

Como antecedente importante se encuentra el trabajo realizado en universitarios de la ciudad de Cali, el cual tuvo por finalidad, indagar sobre las principales prácticas sexuales que ejercen los universitarios; así como, la percepción de riesgo frente a la presencia de ITS. Se menciona que el VIH-SIDA está reconocido ampliamente por los jóvenes como la ITS de mayor riesgo; y que los estudiantes presentan tendencia a cancelar el uso del preservativo al tener una pareja estable (6). De manera similar (7) en el 2012, en la ciudad de Ica se realizó un estudio dónde se buscó determinar los conocimientos, actitudes y prácticas frente al VIH-SIDA en adolescentes de colegios de educación secundaria; si bien no es la misma población a la que hacemos referencia, es importante realizar una comparación ante un estudio de similares características, las cuales están relacionadas a la investigación en curso.

Este estudio es importante, debido a que la falta de conocimiento del tema constituye un problema de salud pública mundial, estando nuestro país y región no ajeno a este; siendo, los grupos etarios más vulnerables el de jóvenes y adultos, por su inmadurez social, emocional y psicológica (8).

El objetivo principal de esta investigación es identificar y comparar los conocimientos, actitudes y prácticas frente al VIH-SIDA en estudiantes de ciencias de la salud, letras y humanidades e ingenierías de una universidad nacional de Ica en el año 2017; así como, las características sociodemográficas relacionadas, con el fin de aportar a la sociedad datos suficientes en el mejor desarrollo de esta población.

\section{MATERIALES Y MÉTODOS}

El tipo de investigación es no experimental, prospectivo, de corte transversal, de carácter descriptivo. La unidad de análisis estuvo constituida por alumnos matriculados en el cuarto año de estudios de las siguientes profesiones: Ciencias de la Salud (Medicina Humana, Enfermería, Odontología, Farmacia), Letras y Humanidades (Contabilidad, Administración, Derecho, Educación Inicial) e Ingenierías (Ingeniería de Sistemas, Ingeniería Civil, Agronomía e Ingeniería Ambiental); de la Universidad Nacional "San Luis Gonzaga de Ica" en el año 2017.

Se realizó un muestreo probabilístico de tipo aleatorio simple, calculando el número de participantes a incluir por cada facultad. Los criterios de inclusión para esta investigación fueron: tener una edad mayor o igual a 18 años, pertenecer a una de las 12 carreras profesionales antes mencionadas, estar matriculados en el cuarto año de estudios y aceptar participar en el estudio voluntariamente. Se realizó un estudio piloto en la Facultad de Medicina para confirmar tiempo del llenado de la encuesta y verificar que no haya errores. Posteriormente, se aplicó en las demás facultades la ficha de recolección de datos socio demográficos, junto al cuestionario confidencial sobre vida sexual activa (9) y Test Escala VIH-SIDA- 65 (10), previa firma del consentimiento informado.

La población total entre las 12 facultades era de 1492 alumnos, con una muestra obtenida de 469 unidades de análisis, con margen de error de $5 \%$, precisión de $3 \%$ y nivel de confianza de $95 \%$. Se recolectaron un total de 498 encuestas, depurando las fichas incompletas, quedando 480 encuestas. Se transfirió la información a una base de datos elaborada mediante el programa SPSS v.23, realizando análisis univariado y bivariado. Se consideró valor significativo a " $p$ " menor de 0,05. Se 
utilizó la Escala de Stanones para medir el nivel de conocimientos, actitudes y prácticas, donde se aplicó una escala de calificación que constó de tres criterios: inferior, intermedio y superior.

\section{RESULTADOS}

Tabla 1: Factores Sociodemográficos de los estudiantes de una universidad nacional de Ica, 2017.

\section{Frecuencia $\quad$ Porcentaje (\%)}

\section{Sexo}

Femenino

50,2

Masculino

\section{Lugar de Procedencia}

Zona Rural

Zona Urbana

\section{Lugar de Residencia}

Zona Rural

Zona Urbana

\section{Religión}

Católica

Evangélica

\section{Fuente: Elaboración propia a partir de ficha de recolección de datos.}

De los 480 estudiantes, el 50,2\% (241) corresponde al sexo femenino y el 49,8\% (239) al masculino, siendo la edad promedio de 22,49 años (19 - 55). El 21,7\% (104) de estudiantes procedían de zonas rurales y el 17,3\% (83) residían en ellas; siendo en mayor proporción los estudiantes de Agronomía. El mayor porcentaje de estudiantes profesaban la religión católica, con un 75,6\% (363) (Tabla N²01).

Tabla 2: Clasificación de la escala de conocimientos entre las facultades de una universidad nacional de Ica y según sexo 2017.

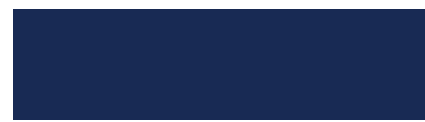

\section{Inferior}

\section{Intermedio Superior \\ $\%$ \\ $\%$}

\section{Total}

\section{Facultades de estudio}

Medicina Humana
Enfermería
Odontología
Farmacia
Contabilidad
Administración
Derecho
Educación Inicial
Ingeniería de Sistemas
Ingeniería Civil

$0,0 \%$

$2,7 \%$

$97,3 \%$

37

$0,0 \%$

$35,7 \%$

$64,3 \%$

28

$100 \%$

$0,0 \%$

$48,9 \%$

$51,1 \%$

45

$100 \%$

$20,6 \%$

$64,7 \%$

$14,7 \%$

34

$100 \%$

$60,0 \%$

$40,0 \%$

$0,0 \%$

$100 \%$

$37,0 \%$

$50,0 \%$

$13,0 \%$

85

$100 \%$

$27,3 \%$

$65,9 \%$

$6,8 \%$

46

$100 \%$

$25,0 \%$

$50,0 \%$

$25,0 \%$

44

$100 \%$

$0,0 \%$

$30,8 \%$

$69,2 \%$

$100 \%$

$0,0 \%$

$100,0 \%$

$0,0 \%$

13

$100 \%$ 


\begin{tabular}{lccccc} 
Agronomía & $2,1 \%$ & $97,9 \%$ & $0,0 \%$ & 48 & $100 \%$ \\
Ingeniería Ambiental & $7,5 \%$ & $\mathbf{7 7 , 5 \%}$ & $15,0 \%$ & 40 & $100 \%$ \\
Total & $\mathbf{2 0 , 0 \%}$ & $\mathbf{5 6 , 9 \%}$ & $\mathbf{2 3 , 1 \%}$ & $\mathbf{4 8 0}$ & $\mathbf{1 0 0 \%}$ \\
Sexo & & & & & \\
Femenino & $19,5 \%$ & $51 \%$ & $29,5 \%$ & $\mathbf{2 4 1}$ & $\mathbf{1 0 0 \%}$ \\
Masculino & $20,5 \%$ & $62,8 \%$ & $16,7 \%$ & $\mathbf{2 3 9}$ & $\mathbf{1 0 0 \%}$ \\
Total & $\mathbf{2 0 , 0 \%}$ & $\mathbf{5 6 , 9 \%}$ & $\mathbf{2 3 , 1 \%}$ & $\mathbf{4 8 0}$ & $\mathbf{1 0 0} \%$ \\
\hline
\end{tabular}

Fuente: Elaboración propia a partir de ficha de recolección de datos

Para el nivel de conocimientos, actitudes y prácticas de los estudiantes se utilizó la Escala de Stanones respectivamente en cada una de ellas, posteriormente, con la Prueba de Kruskal-Wallis se halló la asociación entre el nivel de cada uno de estos, con los grupos de facultades de la universidad de estudio. Así tenemos, que el nivel de conocimientos para el grupo de estudiantes encuestados en total correspondió a una media de 50,89; lo que representa en la escala de Stanones un nivel intermedio (inferior 58 - 97, intermedio $44-57$ y superior 40 - 43; datos no mostrados) y según Facultad de estudios, observamos que casi la mayoría de los estudiantes de la facultad de Medicina presentan un nivel de conocimientos superior $(97,3 \%$ ) y que los estudiantes de contabilidad son los que en mayor proporción presentan conocimientos inferiores (60\%) (Tabla $\left.\mathrm{N}^{\circ} 02\right)$.

Se aprecia que tanto mujeres como varones muestran un nivel intermedio de conocimientos y actitudes frente al VIH-SIDA (Tabla N 02); sin embargo, estos resultados no resultan ser significativos. No se halla una relación significativa entre el nivel de conocimientos y prácticas; además, muestra una tendencia negativa -0,063 en la relación, confirmando la poca asociación entre las variables. De manera contraria, la relación entre conocimientos y actitudes si demuestra ser significativa.

Tabla 3: Escala de conocimientos, actitudes y prácticas por grupos de facultades de una universidad nacional de Ica, 2017.

\begin{tabular}{|c|c|c|c|}
\hline \multirow[b]{2}{*}{ Grupos de Facultades de la UNICA } & \multicolumn{3}{|c|}{ Suma de puntajes } \\
\hline & Conocimientos & Actitudes & Prácticas \\
\hline $\begin{array}{l}\text { Ciencias de la Salud } \\
n=144\end{array}$ & $220,55+$ & $235,46+$ & $135,78+$ \\
\hline $\begin{array}{l}\text { Letras y Humanidades } \\
n=195\end{array}$ & $259,88+$ & $251,71+$ & $218,76+$ \\
\hline $\begin{array}{l}\text { Ingenierías } \\
\mathrm{n}=141\end{array}$ & $234,07+$ & $230,14+$ & $213,11+$ \\
\hline $\begin{array}{l}\text { p valor } \\
\text { (test de Kruskall Wallis) }\end{array}$ & 0.029 & 0.322 & 0 \\
\hline
\end{tabular}

Fuente: Elaboración propia a partir de ficha de recolección de datos

Los universitarios presentan un nivel de actitud intermedio frente al VIH-SIDA según la escala de Stanones, con una media de 29,79 (inferior $34-60$, intermedio $26-33$ y superior $21-25$; datos no mostrados). De modo global, resulta significativo el hallazgo en el que los estudiantes de Ciencias de la Salud presentan mayor nivel de conocimientos y prácticas sexuales (220,55 y 135,78 respectivamente) frente a las otras facultades de letras y Humanidades e Ingenierías, tomando como superior el rango promedio de menor valor; a diferencia de las actitudes que no demostraron certero valor (Tabla $\left.\mathrm{N}^{\circ} 03\right)$. 
Tabla 4: Descripción de los conocimientos correctos e incorrectos frente al VIH-SIDA en los estudiantes de una universidad nacional de Ica, 2017.

$\begin{array}{cccc} & \text { Verdadero } & \text { FALSO } & \text { No sé } \\ & \% & \% & \%\end{array}$

\section{Número de pregunta de conocimientos correctos}

2. Se puede contraer el virus del SIDA compartiendo jeringas con un drogadicto quien tiene la enfermedad

\begin{tabular}{|c|c|c|}
\hline $93,8 \%$ & $2,3 \%$ & $4,0 \%$ \\
\hline $83,8 \%$ & $6,0 \%$ & $10,2 \%$ \\
\hline $75,0 \%$ & $21,3 \%$ & $3,8 \%$ \\
\hline $95,2 \%$ & $2,3 \%$ & $2,5 \%$ \\
\hline $94,4 \%$ & $2,7 \%$ & $2,9 \%$ \\
\hline $96,3 \%$ & $2,3 \%$ & $1,5 \%$ \\
\hline $96,5 \%$ & $2,1 \%$ & $1,5 \%$ \\
\hline $73,8 \%$ & $20,4 \%$ & $5,8 \%$ \\
\hline $92,5 \%$ & $5,0 \%$ & $2,5 \%$ \\
\hline $88,3 \%$ & $5,8 \%$ & $5,8 \%$ \\
\hline $76,9 \%$ & $16,9 \%$ & $6,3 \%$ \\
\hline $76,5 \%$ & $11,0 \%$ & $12,5 \%$ \\
\hline $77,3 \%$ & $12,5 \%$ & $10,2 \%$ \\
\hline $67,1 \%$ & $18,3 \%$ & $14,6 \%$ \\
\hline $92,7 \%$ & $4,2 \%$ & $3,1 \%$ \\
\hline $74,0 \%$ & $6,0 \%$ & $20,0 \%$ \\
\hline $77,7 \%$ & $12,7 \%$ & $9,6 \%$ \\
\hline $64,8 \%$ & $17,5 \%$ & $17,7 \%$ \\
\hline $70,2 \%$ & $19,8 \%$ & $10,0 \%$ \\
\hline $82,5 \%$ & $7,5 \%$ & $10,0 \%$ \\
\hline
\end{tabular}

3. Se puede transmitir el virus del SIDA a través del semen

4. Las personas pueden reducir la probabilidad de llegar a infectarse con el virus del SIDA evitando las relaciones sexuales

6. Hombres con el virus del SIDA pueden infectar a las mujeres

7. El SIDA es una enfermedad que amenaza la vida de la persona

8. Recibir una transfusión de sangre infectada con el virus del SIDA puede transmitirle a una persona el virus del SIDA

9. Las mujeres con el virus del SIDA pueden infectar a los hombres

10. Una persona puede reducir la probabilidad de infectarse con el virus del SIDA no teniendo relaciones sexuales

13. El virus del SIDA se puede transmitir a través de la relación sexual entre un hombre y una mujer

23. Las personas con el virus del SIDA están más propensas a contraer otras enfermedades

24. Los hijos de una madre con el virus del SIDA corren mayor riesgo de contraer el SIDA

25. En la actualidad no hay cura conocida para el SIDA

26. Una persona puede ser infectada con el virus del SIDA y no presentar ningún síntoma de la enfermedad

27. Las personas pueden tener el virus del SIDA en su cuerpo y no estar enfermos

31. El virus del SIDA debilita la capacidad del cuerpo para combatir las infecciones

32. Se puede contraer el virus del SIDA a través de penetración anal

35. El virus del SIDA puede transmitirse entre dos hombres que tengan relaciones sexuales

36. Los homosexuales masculinos corren un alto riesgo de contraer el virus del SIDA

37. Las prostitutas tienen un alto riesgo de contraer el virus del SIDA

40. Se puede contraer el SIDA a través de alguien que está infectado,

aunque no manifiesta ningún síntoma de la enfermedad 


\section{Número de pregunta de conocimientos incorrectos}

1. Se puede saber si una persona tiene el virus del SIDA solo con la mirada

\begin{tabular}{|c|c|c|}
\hline $6,0 \%$ & $84,4 \%$ & $9,6 \%$ \\
\hline $15,0 \%$ & $76,7 \%$ & $8,3 \%$ \\
\hline $13,1 \%$ & $71,3 \%$ & $15,6 \%$ \\
\hline $3,1 \%$ & $92,9 \%$ & $4,0 \%$ \\
\hline $3,8 \%$ & $93,3 \%$ & $2,9 \%$ \\
\hline $4,4 \%$ & $90,2 \%$ & $5,4 \%$ \\
\hline $2,5 \%$ & $89,2 \%$ & $8,3 \%$ \\
\hline $7,1 \%$ & $79,8 \%$ & $13,1 \%$ \\
\hline $3,1 \%$ & $93,1 \%$ & $3,8 \%$ \\
\hline $14,2 \%$ & $67,5 \%$ & $18,3 \%$ \\
\hline $7,1 \%$ & $83,3 \%$ & $9,6 \%$ \\
\hline $21,7 \%$ & $53,1 \%$ & $25,2 \%$ \\
\hline $7,5 \%$ & $84,4 \%$ & $8,1 \%$ \\
\hline $4,4 \%$ & $93,1 \%$ & $2,5 \%$ \\
\hline $2,3 \%$ & $94,4 \%$ & $3,3 \%$ \\
\hline $19,0 \%$ & $66,7 \%$ & $14,4 \%$ \\
\hline $12,5 \%$ & $74,2 \%$ & $13,3 \%$ \\
\hline $2,3 \%$ & $96,3 \%$ & $1,5 \%$ \\
\hline $16,7 \%$ & $66,5 \%$ & $16,9 \%$ \\
\hline $11,0 \%$ & $69,8 \%$ & $19,2 \%$ \\
\hline
\end{tabular}

5. Se puede contraer el virus del SIDA compartiendo cuchillos, tenedores o vasos con una persona infectada

11. Todas las mujeres que tienen relaciones sexuales con otras mujeres tienen el virus del SIDA

12. Uno puede contraer el virus del SIDA tocando o estando cerca de una persona con SIDA

14. Todas las personas con el virus del SIDA son homosexuales

15. Tener el SIDA no es grave, es como estar resfriado

16. El estrés puede causar SIDA

17. Se puede evitar contraer el virus del SIDA haciendo deporte con regularidad

18. Es posible que una persona contraiga el virus del SIDA hablando a través de un teléfono público utilizado por una persona infectada del virus 19. Se puede contraer el virus del SIDA por los asientos de los baños públicos

20. Se puede contraer el virus del SIDA compartiendo la misma habitación con alguien con SIDA

21. Existe un tratamiento médico que puede prevenir la transmisión del virus del SIDA

22. Se puede contraer el virus del SIDA compartiendo la ropa con otra persona con el virus

28. Las personas pueden contraer el virus del SIDA con un simple apretón de manos

29. El SIDA se ha encontrado sólo en los hombres

30. Se puede contraer el virus del SIDA usando objetos personales de otra persona como un cepillo de cabello

33. Se puede contraer el virus del SIDA bebiendo de la misma taza o vaso que una persona con SIDA usó

34. Se puede transmitir el virus del SIDA mediante abrazos

38. El estornudar y el toser pueden transmitir el virus del SIDA

39. Se puede contraer el virus del SIDA en la piscina

$11,0 \%$

$19,2 \%$

\section{Fuente: Elaboración propia a partir de ficha de recolección de datos}

La mayoría de los estudiantes (96,3\%) muestran conocimientos correctos en forma global frente al enunciado: "Las mujeres con el virus del SIDA pueden infectar a los hombres". Sin embargo, se puede evidenciar desconocimiento en regular proporción (20,0\%) frente a la posibilidad de adquirir el virus del SIDA a través de penetración anal. Un $25,2 \%$ (121) muestran ideas incorrectas frente a la posibilidad que el tratamiento médico pueda prevenir la transmisión del virus del SIDA (Tabla $\left.N^{\circ} 04\right)$. 
Tabla 5: Actitudes frente a la infección del VIH-SIDA en estudiantes de una universidad nacional de Ica, 2017.

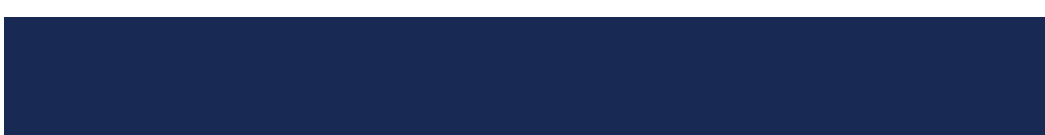

\section{De acuerdo Desacuerdo}

No sé

$\%$

$\%$

$\%$

\section{Número de Pregunta de Actitudes Positivas}

48. Es importante que los estudiantes aprendan sobre el SIDA en clases de comportamiento y salud.

49. Creo que a cualquiera que se inyecte drogas debe realizarse la prueba del virus del SIDA.

57. Debería permitirse que las personas con el SIDA utilicen los buses públicos.

60. Debería permitirse que las personas con el virus del SIDA vivan en unidades residenciales.

61. Debería permitirse que los alumnos que tienen el virus del SIDA asistan a clase.

$\begin{array}{lll}92,3 \% & 6,3 \% & 1,5 \% \\ 75,0 \% & 16,0 \% & 9,0 \% \\ 61,3 \% & 31,3 \% & 7,5 \% \\ 50,6 \% & 35,8 \% & 13,5 \% \\ 76,3 \% & 17,9 \% & 5,8 \%\end{array}$

\section{Número de Pregunta de Actitudes Negativas}

42. Rechazaría sentarme cerca de una persona que tiene el SIDA

$\begin{array}{lll}77,9 \% & 11,9 \% & 10,2 \% \\ 53,1 \% & 34,2 \% & 12,7 \%\end{array}$

persona con el virus del SIDA

$53,1 \%$

$28,1 \%$

$65,0 \%$

$6,9 \%$

la seguridad de los demás

$53,5 \%$

$25,4 \%$

$21,0 \%$

recursos en comparación con otras enfermedades

64. Las personas con el virus del SIDA deberían estar permanentemente aisladas de los demás

$85,0 \% \quad 6,0 \% \quad 6 \%$

\section{Número de Pregunta de Actitudes Neutras}

46. Elegir el tipo de condón que se va a comprar puede resultar difícil

$19,6 \%$

$61,3 \%$

$19,2 \%$

56. El sexo no es tan placentero cuando se usa condón

$38,3 \%$

$42,5 \%$

$19,2 \%$

59. Parar durante el acto sexual para ponerse un condón hace el sexo menos divertido

$23,3 \% \quad 58,5 \% \quad 18,1 \%$

62. Creo que es muy importante usar condones cada vez que se tengan relaciones sexuales

$91,5 \% \quad 5,6 \% \quad 2,9 \%$

63. Resulta difícil encontrar sitios donde comprar condones

$19,6 \%$

$70,8 \%$

$9,6 \%$

\section{Fuente: Elaboración propia a partir de ficha de recolección de datos}

El 50\% de encuestados muestran actitudes positivas frente a la infección del VIH-SIDA, dentro de los cuales están de acuerdo en que es importante que los estudiantes aprendan sobre el SIDA en clases de comportamiento y salud (92,3\%) (Tabla $N^{\circ} 05$ ). El 65\% de participantes refieren estar de acuerdo con que las personas con SIDA deberían ser aisladas para garantizar la seguridad de los demás, siendo una actitud negativa. Por otro lado, el 91,5\% de estudiantes cree muy importante el uso de condones cada vez que se tengan relaciones sexuales (Tabla $\mathrm{N}^{\circ} 05$ ). 
Tabla 6: Descripción de la autoeficacia frente a la infección del VIH-SIDA en los estudiantes de una universidad nacional de Ica, 2017.

\begin{tabular}{lccccccccc}
\multicolumn{1}{c}{ Número de pregunta } & \multicolumn{1}{c}{ De Acuerdo } & \multicolumn{3}{c}{ Desacuerdo } & \multicolumn{2}{c}{ No sé } & \multicolumn{2}{c}{ Total } \\
& $\mathbf{N}$ & $\%$ & $\mathbf{N}$ & $\%$ & $\mathbf{N}$ & $\%$ & $\mathbf{N}$ & $\%$ \\
\hline $\begin{array}{l}\text { 41. Soy capaz de pedirle a mi pareja sexual que use un } \\
\text { condón. }\end{array}$ & 448 & $93,3 \%$ & 14 & $2,9 \%$ & 18 & $3,8 \%$ & 480 & $100 \%$ \\
$\begin{array}{l}\text { 47. Soy capaz de comprar o conseguir condones } \\
\text { fácilmente. }\end{array}$ & 153 & $31,9 \%$ & 271 & $56,5 \%$ & 56 & $11,7 \%$ & 480 & $100 \%$ \\
$\begin{array}{l}\text { 52. Soy capaz de preguntarles a mi pareja si ha tenido } \\
\text { relaciones sexuales con alguien que se prostituya. }\end{array}$ & 112 & $23,3 \%$ & 332 & $69,2 \%$ & 36 & $7,5 \%$ & 480 & $100 \%$ \\
$\begin{array}{l}\text { 54. Soy capaz de contarle a mi pareja si he tenido } \\
\text { relaciones sexuales con una persona bisexual. }\end{array}$ & 124 & $25,8 \%$ & 278 & $57,9 \%$ & 78 & $16,3 \%$ & 480 & $100 \%$ \\
$\begin{array}{l}\text { 55. Soy capaz de llevar condón por si decido tener } \\
\text { relaciones sexuales. }\end{array}$ & 376 & $78,3 \%$ & 54 & $11,3 \%$ & 50 & $10,4 \%$ & 480 & $100 \%$ \\
\hline
\end{tabular}

\section{Fuente: Elaboración propia a partir de ficha de recolección de datos}

El 93,3\% (448) de los estudiantes refieren ser capaces de solicitar a su pareja sexual el uso del condón. Se observa que un gran porcentaje de estudiantes $78,3 \%$ (376), refiere ser capaz de poder llevarlos por si decide tener relaciones sexuales. No demostrando tan buena autoeficacia al afirmar si eran capaces de cuestionar a su pareja por si ha tenido relaciones sexuales con alguien que se prostituya $(69,2 \%)$ (Tabla $\left.N^{\circ} 06\right)$.

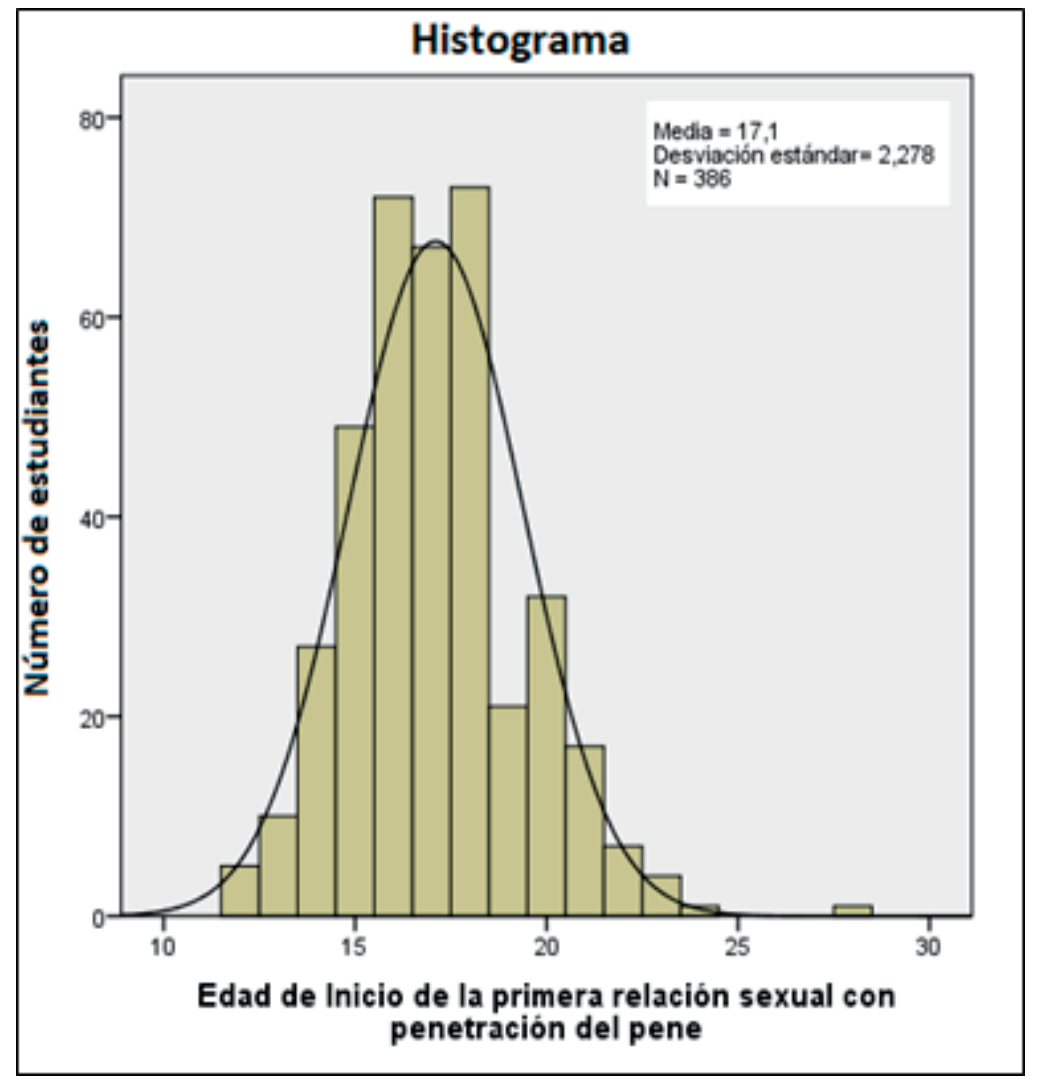

Figura 1: Distribución de edad sobre el inicio de la relación sexual con penetración de los estudiantes de una universidad nacional de Ica, 2017.

Dentro de las prácticas sexuales el $80,4 \%$ de los estudiantes afirman ya haber tenido alguna forma de relaciones sexuales con penetración: vaginal $(76,5 \%)$; oral $(42,9 \%)$ y anal $(30,6 \%)$; mientras que el $19,6 \%$ refirieron no haber tenido aún relaciones sexuales de esta categoría (datos no mostrados). La edad de inicio de relaciones sexuales con penetración reflejada en el estudio oscila entre los 15 y 18 años con un 39,2\% y en menor porcentaje, el 8,8\% antes de los 15 años (Figura 1). 
En la primera relación sexual el 47,5\% de estudiantes refiere haber hecho uso del condón, mientras que en la última relación sexual lo afirma el 53,4\% de encuestados. El 46,7\% de estudiantes que no hicieron uso del preservativo, justifica su actitud debido a que confían en la persona con quien tuvo esa relación. En los últimos doce meses los estudiantes afirman haber mantenido relaciones sexuales con penetración con al menos 2 personas, siendo el valor mínimo 1 y el máximo de 13 personas. Además, el 90,2\% afirma haber tenido relaciones sexuales con personas del sexo opuesto; 9,5\% con personas de su mismo sexo y $0,3 \%$ con ambos sexos. Así mismo, el 74,1\% estudiantes afirma haber tenido relaciones con penetración en la vagina y de ellos solo el 25,5\% refiere haber usado condón en todas las ocasiones (datos no mostrados).

\section{Figura $\mathrm{N}^{\circ} 02$.}

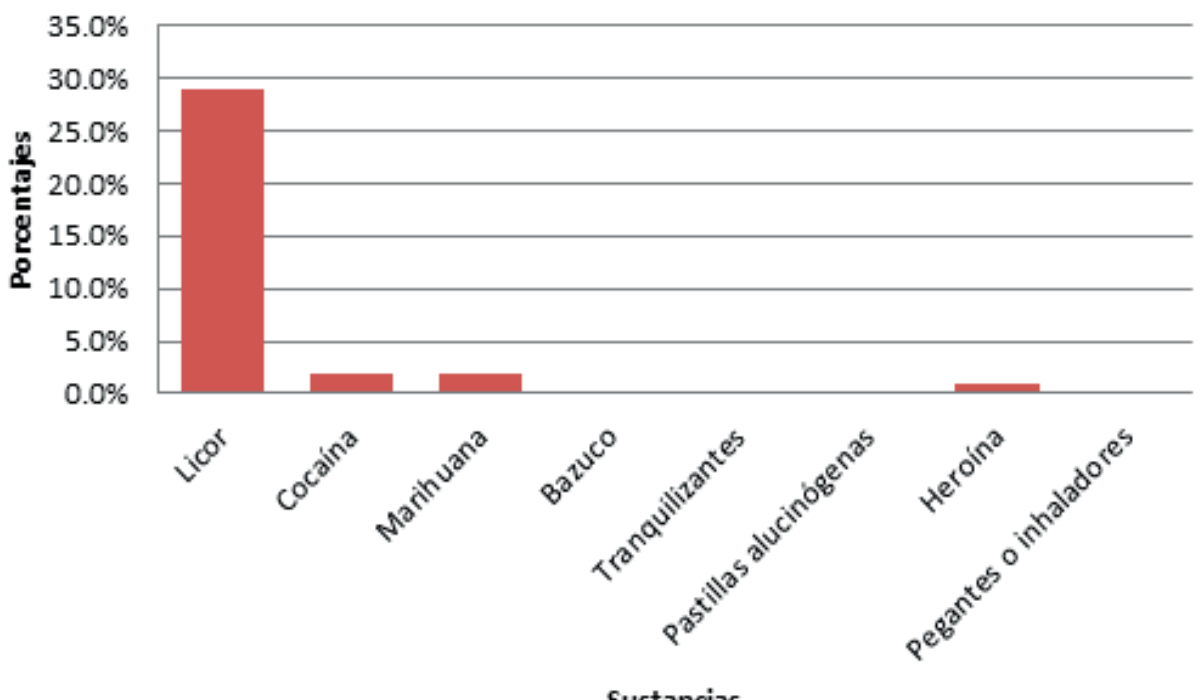

Figura 2: Sustancias más usadas durante las prácticas sexuales en los últimos 12 meses, por parte de los estudiantes de una universidad nacional de Ica, 2017.

En el estudio realizado, el 29,9\% de los encuestados afirma haber estado principalmente bajo efectos de licor en sus prácticas sexuales en los últimos doce meses (Figura $\mathrm{N}^{\circ} 02$ ).

Tabla 7: Medidas preventivas para evitar la transmisión del VIH-SIDA en los últimos 12 meses por parte de los estudiantes de una universidad nacional de Ica, 2017.

\begin{tabular}{|c|c|c|c|}
\hline Número de pregunta & $\begin{array}{l}\text { Sí } \\
\%\end{array}$ & $\begin{array}{c}\text { No } \\
\%\end{array}$ & $\begin{array}{c}\text { Total } \\
\%\end{array}$ \\
\hline 17 A. Tener relaciones sexuales sólo con una misma persona. & $50,8 \%$ & $49,2 \%$ & $100 \%$ \\
\hline 17 B. Usar condón. & $73,1 \%$ & $26,9 \%$ & $100 \%$ \\
\hline $\begin{array}{l}17 \mathrm{C} \text {. Conversar con la(s) personas(s) con la(s) que ha tenido } \\
\text { relaciones sexuales sobre el riesgo que tienen de adquirir el virus. } \\
17 \mathrm{D} \text {. Ponerse de acuerdo con la(s) persona(s) con la(s) que ha } \\
\text { tenido relaciones sexuales sobre el uso de medidas de protección. }\end{array}$ & $63,7 \%$ & $36,3 \%$ & $100 \%$ \\
\hline
\end{tabular}

\section{Fuente: Elaboración propia a partir de ficha de recolección de datos}

Los participantes muestran una actitud favorable para adoptar medidas preventivas y evitar adquirir VIH-SIDA, con el uso del condón (73,1\%), y mediante el acuerdo y diálogo sobre medidas de protección con sus parejas (69,9\%) (Tabla $\mathrm{N}^{\circ}$ 07). 


\section{DISCUSIÓN}

En el Perú, la población juvenil universitaria representa un gran porcentaje de la población total, mostrándose vulnerables a la exposición de factores de riesgo frente a las infecciones de transmisión sexual, adicciones y otros problemas sociales. El Centro de Epidemiología, Prevención y control de Enfermedades revelaron que las personas entre 25 y 34 años eran quienes constituían el grueso de casos de VIH-SIDA, durante el periodo de tiempo de 1983 al 2017 (3); siendo necesario intervenir en esta población para lograr instaurar o reforzar buenos conocimientos sobre el tema y lograr la prevención de esta infección.

En nuestro trabajo hallamos que varones y mujeres muestran un nivel de conocimientos intermedios; siendo los primeros quienes obtienen valores ligeramente superiores a las mujeres (Tabla $\mathrm{N}^{\circ}$ 02). Estos datos concuerdan con otros trabajos del Estado de los Emiratos Árabes Unidos y Tanzania que afirman de manera similar que los varones presentan conocimientos sobre VIH-SIDA superiores al de las mujeres $(11,12)$. También se ha reportado que el $66,7 \%$ de la población femenina presenta nivel de conocimientos regulares y en mucho menor porcentaje conocimientos buenos (8,6\%) (15). Sin embargo, otro estudio no encontró asociación entre el puntaje de conocimientos con ninguna de las variables independientes presentadas, entre ellas, el género de la persona (13).

Nuestra población de estudio muestra un nivel de conocimientos intermedios frente al VIH-SIDA, con puntaje de 50,89+8,78, que es inferior en comparación con el puntaje obtenido en el rubro de conocimientos $(66 \pm 10,3)$ en otro estudio realizado en Medellín, Colombia (14); identificando un perfil menos favorable, que se puede atribuir a la diferencia de esfuerzos e inversión de recursos en educación y desarrollo social de cada país.

En la relación del nivel de conocimientos sobre $\mathrm{VIH}$-SIDA con la carrera profesional, muestran superioridad mínima en los alumnos de ciencias de la salud respecto a los de ingeniería, así como lo han mostrado otros estudios $(15,16)$. Estos resultados podríamos atribuirlos a que los universitarios que cursan los últimos años de estudio en facultades de ciencias de la salud cuentan con mayor experiencia en la práctica hospitalaria y desarrollan numerosos cursos teóricos relacionados a esta enfermedad.

También se muestra que los estudiantes tienen conocimientos incorrectos en la forma de transmisión del virus (Tabla $\mathrm{N}^{\circ}$ 04). Cuando este punto, es el de mayor énfasis al realizar educación y prevención de esta enfermedad. Resalta el ejemplo de que aún se crea que el VIH se pueda transmitir por el uso de asientos, baños públicos o de objetos personales de otra persona como un cepillo de cabello. A más de 25 años del descubrimiento del VIH-SIDA, este panorama despierta preocupación, lo que reafirma la importancia de intervención en esta población.

Anteriormente, se ha reportado en la facultad de enfermería de la misma universidad, un alto nivel de conocimiento (99\%) y actitudes favorables (85\%) sobre VIH-SIDA; siendo porcentajes muy aceptables para una rama de Ciencias de la salud. De manera similar a nuestro estudio, el área de ciencias de la salud respecto a las demás facultades demuestra tener mejores prácticas sexuales y nivel de conocimiento frente al VIH-SIDA (Tabla $\mathrm{N}^{\circ}$ 03), correlacionando mejores conocimientos, mejores prácticas sexuales. Resaltamos que dentro de las prácticas favorables se ha considerado aquellos estudiantes que aún no han iniciado su vida sexual $(6,7)$.

En análisis del sexo biológico con nivel de actitudes y prácticas, demostró que mujeres y varones presentan niveles intermedios, siendo mayor por parte de los varones en el rubro de prácticas sexuales (Tabla $\mathrm{N}^{\circ} 02$ ). Respecto a las actitudes positivas, el 92,3\% de nuestra muestra afirma: es importante que los estudiantes aprendan sobre el SIDA en clases de comportamiento y salud. Por otra parte, el $65 \%$ de los encuestados está a favor de que las personas con SIDA deben ser aisladas para garantizar la seguridad de los demás; una actitud negativa que llama la atención, pues a pesar de poseer un nivel intermedio de conocimientos, estos pueden verse influenciados por tabúes o estigmas propios.

Algunos estudios(18) señalan que las personas infectadas por VIH que no conocen su estado serológico realizan más prácticas sexuales de riesgo que las personas diagnosticadas, elevando aproximadamente 3,5 veces la transmisión del virus; lo que demuestra la importancia de un diagnóstico temprano. El comportamiento sexual es considerado como una práctica, por ser construido y compartido socialmente (19). Los conocimientos, actitudes y prácticas de sexualidad de la población adolescente se relacionan con la estructura del hogar y la percepción de los jóvenes acerca de la funcionalidad de este.

La edad de inicio de las relaciones sexuales es de relevante importancia, debido a que la mayor tasa de transmisión del VIH es por vía sexual (20). Los factores asociados a una edad temprana son baja autoestima, iniciación de la vida sexual en los amigos, desintegración familiar, poca comunicación entre padres y adolescentes, percepción de madurez física, abandono de los estudios, mal uso del tiempo libre y presión de la pareja (21). En base al cuestionario aplicado, tenemos como edad de inicio de relaciones sexuales con penetración entre los 15 a 18 años (48,7\%), seguido de los mayores de 18 años $(40,4 \%)$ y en menor porcentaje antes de los 15 años 
$(10,9 \%)$; similar a los otros estudios realizados en la ciudad de Ica (7), donde obtienen como edad de inicio de las relaciones sexuales de 14,31 1,55 años. Nuestros resultados muestran que las facultades del área de la salud fueron quienes más retrasaron su primera relación sexual con penetración.

A pesar de que el VIH-SIDA está reconocido ampliamente por los jóvenes, en su gran mayoría como la ITS de mayor riesgo, aún es poco común el uso del preservativo como medio de protección; que está demostrado, es un elemento crucial para un enfoque integral y sostenible de la prevención del VIH y otras infecciones de transmisión sexual (ITS) y de embarazos no deseados (1).

Según la Encuesta Demográfica y de Salud Familiar (ENDES 2015), sólo el 9,7\% de adolescentes entre los 15 y 19 años utilizó condón masculino en su primera relación sexual. A pesar de estos datos, el $46,6 \%$ de los jóvenes no usaron condón en la última relación sexual, como causa principal, la confianza en su pareja estable, siendo predominante la tendencia a cancelar el uso del preservativo, como un símbolo de fidelidad y compromiso (13).

Algunas actividades sexuales son más riesgosas que otras para obtener o transmitir el $\mathrm{VIH}$; Claro ejemplo, es que una persona seronegativa sea el socio receptivo ("pasivo") en el sexo anal (22). El riesgo de las actividades como el sexo oral, las caricias y los besos es pequeño o inexistente en lo que se refiere al contagio o la transmisión del VIH $(24,25)$. Diversos estudios a nivel de Perú y Latinoamérica $(23,26)$ informan que los varones presentan mayor variedad de experiencias sexuales que las mujeres.

Según Bermúdez y cols (23), las mujeres en mayor proporción no utilizaron preservativo en la primera relación sexual anal y presentaron mayor índice de riesgo de esta práctica frente a los varones; lo que nos hace suponer como causa, el que muchos jóvenes utilizan el preservativo para evitar embarazos no deseados, mas no como medio de protección contra ITS; y el posible desconocimiento del canal anal como vía de transmisión.

Respecto a las conductas de riesgo paralelas a las prácticas sexuales con penetración, se evidencia que en los últimos doce meses el $29 \%$ de los estudiantes estuvo bajo efectos del alcohol, y en segundo lugar por drogas (Figura $\mathrm{N}^{\circ}$ 02). El consumo previo de sustancias es un factor determinante en la adopción de conductas de riesgo, específicamente en el inicio de las relaciones sexuales en los adolescentes (21). Los jóvenes reconocen al alcohol como una de las sustancias más populares que se encuentran a su alcance, permitiéndoles involucrarse en experiencias más arriesgadas y aumentar la excitación entre ellos (27). Diversos estudios sustentan $(6,13,28)$ a la euforia del momento y a todos estos factores como influyentes en el no uso del preservativo.

De acuerdo con nuestros resultados creemos que es necesario facilitar espacios adecuados para la adquisición o reforzamiento de conocimientos en el tema de $\mathrm{VIH}$-SIDA, por parte del equipo educativo universitario en todas las facultades; con el fin de modificar actitudes negativas de nuestros estudiantes e influir para que realicen con seguridad sus prácticas sexuales previniendo la infección por el VIH y otras ITS.

Esperamos que esta investigación sirva de base para futuros estudios y sea considerado en la reestructuración académica en los primeros años de estudios universitarios, ya que ha quedado demostrado la importancia de la educación en este tema, debería iniciar en los colegios y reforzarse en la universidad. Los estudios futuros deben evaluar el comportamiento sexual de riesgo del estudiante universitario, así como las actitudes hacia las personas que viven con el $\mathrm{VIH}$, para ayudar a proporcionar una comprensión integral y reforzar conocimientos de los problemas sexuales entre los estudiantes universitarios.

\section{CONCLUSIONES}

Los estudiantes de la Universidad Nacional San Luis Gonzaga de Ica, en el año 2017, poseen un nivel intermedio de conocimientos $(50,89 \pm 8,775)$, actitudes $(29,79 \pm 4,747)$ y prácticas $(19,88 \pm 10,51)$ frente al VIH-SIDA. Los estudiantes del área de ciencias de la salud tienen mayor nivel de conocimientos y prácticas frente al VIH-SIDA respecto a las otras áreas como Ingenierías y Humanidades. El nivel de conocimientos guarda poca asociación con las prácticas frente al VIH-SIDA, pero no con el nivel de actitudes, y aún existen actitudes negativas hacia la persona infectada con $\mathrm{VIH}$. 


\section{REFERENCIAS BIBLIOGRÁFICAS}

1. Organizacion Mundial de la Salud. VIH/SIDA nota descriptiva $n^{\circ} 360.2013$.

2. PAHO/WHO Institutional Repository. (2018). Prevención de la infección por el VIH bajo la lupa. Un análisis desde la perspectiva del sector de la salud en América Latina y el Caribe. [Online].; 2017. Available from:

http://iris.paho.org/xmlui/handle/123456.

3. Centro Nacional de Epidemiología, Prevención y control de enfermedades - MINSA. Situación del VIH-SIDA en el Perú. Boletín Epidemiológico Mensual. Abril 2016.

4. ONUSIDA. UNAIDS.org. [Online].; 2018 [cited 2018 marzo 20. Available from:

http://www.unaids.org/es/regionscountries/countri es/peru.

5. Ministerio de Salud del Perú. [Online].; 2017 [cited 2018 Enero 20. Available from:

http://www.minsa.gob.pe/?op $=51 \&$ nota $=25679$.

6. Orcasita LT, López A, Gómez C. Conocimientos sobre riesgos frente a infecciones de transmisión sexual (ITS) en estudiantes universitarios de la ciudad de Cali-Colombia. Med. U.P.M. 2014; 14(1): p. $143-158$.

7. Huaranga-Bravo J, Miranda Soberón U, Medrano Huallanca M, Carhuancho Arango, Sulca Díaz O. Conocimientos, Actitudes y Prácticas frente al VIH/SIDA en estudiantesde educación secundaria de una provincia peruana, 2012. Ica.

8. ONUSIDA. Los niños y los jóvenes en un mundo con SIDA. [Online]; 2001 [cited 2018 marzo 19. Available from:

http://www.unaids.org/sites/default/files/media_as set/jc656-child_aids_es_0.pdf.

9. Contrera F, Carrobles JA, Juarez Acosta F. Propiedades psicométricas del "Cuestionario confidencial de vida sexual activa" para evaluar conductas de riesgo en $\mathrm{VIH}-$ Sida. Behavioral Phychology. ; 15(1): p. 5-27.

10. Maldonado Cervera AL, Castillo L. Psicologia Online. [Online]. [cited 2016 febrero 20. Available from: http://www.psicologia-online.com/ciopa2001/activi dades/p/69/index.html.

11. Haroun D, El Saleh O, Wood L, Mechl R, Al Marzouqi $\mathrm{N}$, Anouti S. Assessing Knowledge of, and Attitudes to, HIV/AIDS among University Students in the United Arab Emirates. PLOS ONE. 2016 February; 11(2).

12. Mkumbo K. Assessment of HIV/AIDS knowledge attitudes and behaviours among students in higher education in Tanzania. Global Public Health. 2013 Octubre; 8(10).

13 Mazo-Vélez , Domínguez-Domínguez LE, Cardona-Arias JA. Conocimientos, actitudes y prácticas en adolescentes universitarios entre 15 y 20 años sobre VIH/SIDA en Medellín, Colombia 2013. revista de los estudiantes de medicina de la universidad industrial de santander. 2014; 27(3): p. 35-45.

14. Cardona Arias JA, Hernández JC, Suárez GR, Zapata W. Conocimientos actitudes y prácticas sobre VIH/ SIDA en estudiantes de educación media de Medellín. iMedPub Journals. 2015; 11(4:10).

15. Díaz Montes CE, Cantillo Uribe L, García Vergara K, Martínez Marenco , Vega Recuero J. CONOCIMIENTOS SOBRE VIH/SIDA EN ADOLESCENTES DE UNA UNIVERSIDAD EN CARTAGENA - COLOMBIA, 2011. Hacia la Promoción de la Salud. 2014 julio - diciembre; 19(2): p. 38-52.

16. Smith L, La Place L, Menn M, Wilson KL. HIV-related knowledge and perceptions by academic major: implications for university interventions (USA).. Front Public Health. 2014 March; 2(18).

17. Enríquez Negrete DJ, Sánchez Medina R. Retraso del debut sexual en universitarios: el papel de los padres, la pareja y los conocimientos sobre VIH / SIDA / ITS /condón. Psicología Iberoamericana. 2016 diciembre; 24(2): p. 34-43.

18. Marks G, Crepaz N, Janssen R. Estimating sexual transmission of HIV from persons aware and unaware that they are infected with the virus in the USA. AIDS. 2006; 20(10).

19. Bahamón Muñetón MJ, Vianchá Pinzón MA, Tobos Vergara AR. Prácticas y conductas sexuales de riesgo en jóvenes: una perspectiva de género. Psicología desde el Caribe. 2014; 31(2).

20. (gTt-VIH) GdTsTdV. HIV testing and risks of sexual transmission (3rd edition). [Online].; 2016 [cited 2018 marzo $19 . \quad$ Available from: http://gtt-vih.org/files/active/0/GUIA_transmision_s exual_web_2Edi.pdf.

21. Jumbo Cedillo IC. Factores psicosociales relacionados con el inicio de la vida sexual en adolescentes del Colegio Pío Jaramillo Alvarado Loja 2014. 2016. [Tesis de Pregrado]. Loja: Facultad de Medicina Humana, Universidad Nacional de Loja; 2016.

22. CDC. Centros para el Control y la Prevención de Enfermedades. [Online].; 2016 [cited 2018 febrero 20. Available from: https://www.cdc.gov/hiv/spanish/risk/analsex.html.

23. Bermúdez MP, Ramiro MT, Teva I, Ramiro-Sanchez T, Buela-Casal G. Conducta sexual y realización de la prueba del virus de la inmunodeficiencia humana en jóvenes que estudian en la universidad en Cuzco (Perú). Gaceta Sanitaria. 2017.

24. Sultan B, Benn $P$, Waters L. Current perspectives in HIV post-exposure prophylaxis. HIV/AIDS-Research and Palliative Care. 2014; 6: p. 147-158.

25. CDC. Centros para la Prevención y Control de Enfermedades. [Online]. Available from: https://www.cdc.gov/hiv/spanish/risk/vaginalsex.ht $\mathrm{ml}$. 
26. Killoren SE, Deutsch AR. A Longitudinal Examination of Parenting Processes and Latino Youth's Risky Sexual Behaviors. Journal of Youth and Adolescence. 2014; 23(12).

27. Trujillo León J. EXPECTATIVAS SOBRE EL CONSUMO DE ALCOHOL Y CONDUCTAS SEXUALES RIESGOSAS EN JÓVENES ESTUDIANTES. [Tesis para optar el título de Licenciada en Psicología].Lima: Pontificia Universidad Católica del Perú; 2015.
28. Dingeta T, Oljira L, Assefa N. Patterns of sexual risk behavior among undergraduate university students in Ethiopia: a cross-sectional study. Pan African Medical Journal. 2012; 12(33).

\section{Las ediciones anteriores de revista médica PANACEA están disponibles en:}

\section{www.revpanacea.unica.edu.pe}

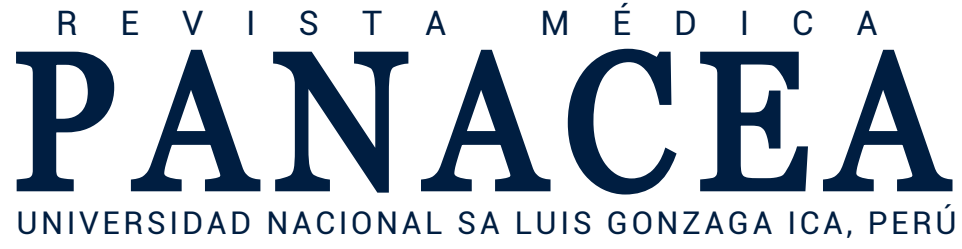

